\title{
A NOVEL APPROACH FOR DETECTING, LOCALISING AND CHARACTERISING DAMAGES IN GLASS FIBRE REINFORCED POLYMER (GFRP) USING THE DROP WEIGHT IMPACT TESTER
}

\author{
N. Razali ${ }^{1}$, M.T.H. Sultan ${ }^{2}$ \\ ${ }^{1}$ Aerospace Manufacturing Research Centre (AMRC), Level 7, Tower Block, Faculty of Engineering, Universiti Putra \\ Malaysia, 43400 UPM Serdang, Selangor DarulEhsan, Malaysia \\ ${ }^{2}$ Aerospace Manufacturing Research Centre (AMRC), Level 7, Tower Block, Faculty of Engineering, Universiti Putra \\ Malaysia, 43400 UPM Serdang, Selangor DarulEhsan, Malaysia
}

\begin{abstract}
The aim of this work is to conduct an experimental study of a low velocity impact test by changes in the type of materials, number of layers and impact energy level using an IM10 Drop Weight Impact Tester. The composite material used in this study was Glass Fibre Reinforced Polymer (GFRP) in two forms:Type C-glass $600 \mathrm{~g} / \mathrm{m}^{2}$ and Type E-glass $600 \mathrm{~g} / \mathrm{m}^{2}$. These materials were fabricated using a hand lay-up technique to produce laminated plate specimens with a dimension of $100 \mathrm{~mm} \times 150 \mathrm{~mm}$. Each type of specimen was fabricated into 10 layers, 12 layers and 14 layers of GFRP woven roving plies. The low velocity impact test was performed using an IM10 Drop Weight Impact Tester with $10 \mathrm{~mm}$ hemispherical striker cap. The impact energy was set to 14, 28, 42 and 56 Joule with velocity ranging from $1.73 \mathrm{~m} / \mathrm{s}$ to $3.52 \mathrm{~m} / \mathrm{s}$ for 10 layer specimens and 7, 14, 21, 28, 35, 42, 49 and 56 Joule for 12 layer and 14 layer specimens. The relationships between impact energy andimpact force, displacement, damage area and energy absorbed are presented. The comparison and behaviour between the two types of GFRP is discussed.
\end{abstract}

Keywords: Low Velocity Impact (LVI), Glass Fibre Reinforced Polymer (GFRP), Energy Absorbed, Drop Weight Impact Tester

\section{INTRODUCTION}

Since composites were introduced in industry, damage from unexpected impact eventse.g.the dropping of hand tools during maintenance work, has seemed to be a problem. A study has been conducted over a few types of compositesconcerning impact damage [1-4]. A low velocity impact (LVI) - which is less than $11 \mathrm{~m} / \mathrm{s}$ - may cause damage [5]. However, some consider impact velocities for LVI to beup to $40 \mathrm{~m} / \mathrm{s}$ [6]. When this material issubjected to low velocity impacts, the structural integrity, stiffness and toughness of the material are all significantly reduced and this will lead to the catastrophic failure of the structure [7]. The possible damage mechanisms that composite laminates may face in the event of low velocity impacts are delimitation, matrix cracking, matrix breakage, fibre cracking, fibre breakage, and fibre pullout [8]. In lowvelocity impacts, internal damage is hard to detect, but it may considerably reduce the capacity of the laminate to support loads. It is therefore important to relate the shape and dimensions of the damage to the geometric characteristics of the sample, the boundary conditions and the test parameters (impact velocity, energy, maximum force, etc.), to better understand the damage mechanisms [9].Due to the increasing focus on the impact problem, it is important to study low velocity impact damage.
According to Tita, if an object with mass $m$ impacts a composite plate with a velocity $v_{0}$, the impact energy of the impacter $E_{i}$ can be expressed by Equation 1 [10]:

$$
E_{i}=\frac{m v_{0}}{2}
$$

The characterisation of the impact tests was based on the conservation of energy principle, where the potential energy (PE) before the impact event is assumed to be equal to the kinetic energy (KE) after the impact event $[11,12]$. Based on Sultan et al.[13],this leads to an impact velocity as shown in Eq. (2):

$$
v=\sqrt{2 g h}
$$

where $\mathrm{v}=$ velocity at impact, $\mathrm{h}=$ drop height, and $\mathrm{g}=$ acceleration ofgravity.

Most composites are brittle and so can only absorb energy in elastic deformation and through damage mechanisms, and not by plastic deformation [14]. From Mathivanan's paper, the energy absorbed can be calculated using the area under the graph of force versus displacement as shown in Figure 1. 


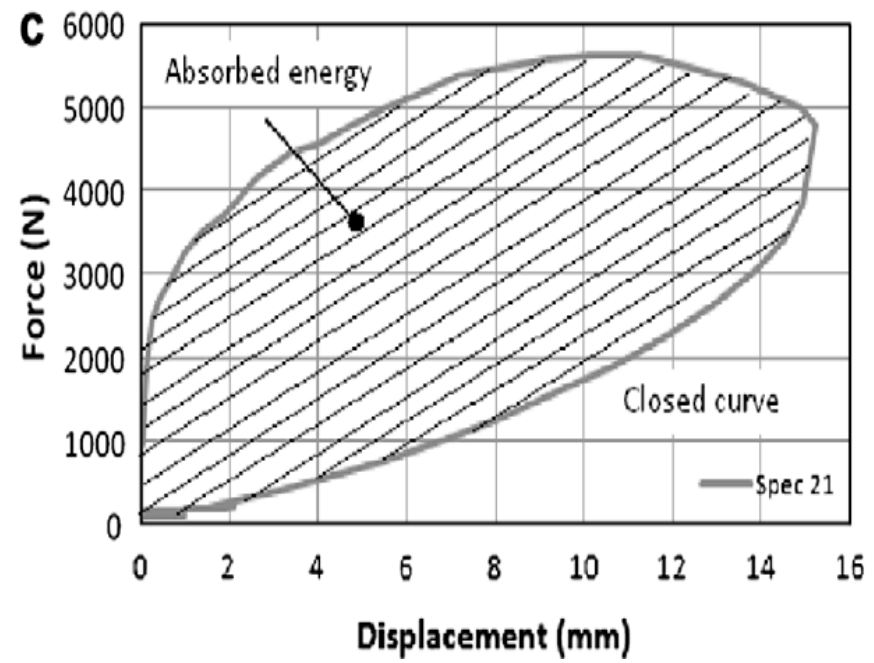

Fig 1: Energy absorbed can be calculated as the area under the graph/closed curve of the Force versus Displacement

Zhang and Richardson [15] revealed that there was a significant reduction in flexural properties due to the impactinduced damage and that the residual flexural strength is more susceptible to damage than the residual modulus.

According to Abrate, non-destructive evaluation techniques can be used to determine the principal failure mechanisms that occur when a composite structure is impacted. However, destructive evaluation techniques are used in order to verify furtherdetails about the failure mechanisms. In fact, non-destructive and destructive techniques are used in conjunction to improve the information quality, increasing the accuracy of inspection results, but this approach also increases the costs [16]. In this work, only the NDE using the dye penetrant technique and the microscope image viewed was used, due to a lack of other NDE equipment.A literature review on recent research on low velocity impact for various types of composite, especially for glass fibre, in order to compare the method of testing and the findingshas been performed [17-30].

\subsection{Aim and Objectives of the Study}

The general objective of this study is to conduct an experimental investigation concerning changes in the test specimen's number of layers and the impact energy level using an IM10 Drop Weight Impact Tester. The specimen is modelled as a rectangular plate with dimensions of $100 \mathrm{~mm}$ $\times 150 \mathrm{~mm}$. The specific objectives of this study are stated as follows:

(a) To examine the impact force, impact energy, energy absorbed, damage area, displacement and the effect of low velocity impact corresponding to different numbers of layers and the impact energy level between two types of fibreglass- Type Cglass/Epoxy $600 \mathrm{~g} / \mathrm{m}^{2}$ and Type E-glass/Epoxy 600 $\mathrm{g} / \mathrm{m}^{2}$ - using an IM10 Drop Weight Impact Tester.

(b) To observe the type of failure between the two types of fibreglass using a non-destructive technique.

\section{EXPERIMENTAL WORK}

\subsection{Material and Test Specimen}

The material used for this investigation is Glass Fibre Reinforced Polymer (GFRP) from Type C-glass/Epoxy 600 $\mathrm{g} / \mathrm{m}^{2}$ and Type E-glass/Epoxy $600 \mathrm{~g} / \mathrm{m}^{2}$. The mainreasonforselecting this material isbecause this material has been used widely in aerospace applications. Furthermore, this material is a low cost material and it does perform as wellas other materials.

\subsection{Specimen Fabrication}

The specimens were prepared using a hand lay-up method on the glass surface. Large panels were produced with a size of $350 \mathrm{~mm} \times 350 \mathrm{~mm}$ with 10 layers, 12 layers and 14 layers of GFRP woven roving plies oriented in the same $0^{0}$ directions. The purpose of selecting this dimension is that, after the curing process, the large panelswillthen be cut into $100 \mathrm{~mm} \times 150 \mathrm{~mm}$ rectangular plates for testing purposes, which will be placed on the clamping unit for the drop test. In order to produce a smooth surface for the specimens, a glazing wax is applied thoroughly to all the surface. This glazing wax also functions as a release agent so that the large panel can easily beremoved from the glass after the curing process. This will prevent the specimens from sticking to the surface area once it is cured. This glazing wax is applied on both sides of the glass. The epoxy resins/hardeners that have been used in this experimental study are from types Zeepoxy HL002TA and Zeepoxy HL002TB which have low viscosity that allows easy handling and give good wetting of reinforcements and substrates. Table 1 shows the physical properties of the epoxy.

Table 1: Physical Properties of the epoxy resin/hardener

\begin{tabular}{|l|l|l|l|}
\hline Item & Unit & TA & TB \\
\hline Appearance & $\begin{array}{l}\text { Colourless } \\
\text { viscous } \\
\text { liquid }\end{array}$ & $\begin{array}{l}\text { Colourless } \\
\text { liquid }\end{array}$ \\
\hline Viscosity & Cps @ 30ㄷ & $5500 \pm 1000$ & $30 \pm 20$ \\
\hline $\begin{array}{l}\text { Mixing } \\
\text { Ratio }\end{array}$ & & $2 \mathrm{~kg}$ & $1 \mathrm{~kg}$ \\
\hline
\end{tabular}

The process of preparing the compound was based on the 2:1 ratio; which is 2 portions of epoxy resin and 1 portion of epoxy hardener. Normal health and safety precautions should be observed when handling this epoxy because it can cause serious health problems. This should involvegood ventilation and wearinggloves and safety glasses. After the mixing process, the compound can be cured at room temperature. The compound should be laid up within 10-15 minutes because the mixture can become hardened and thennot useable for lay-up.During thelay-up process, the excess epoxy resin will be squeezed throughout the composite using a metal roller. Once the lay-up process is complete, the glass with glazing wax on the surface will be put on top of the composite. Finally, the uniform weight will be placed on the top in order to get a smooth surface and remove all excess resin. The curing process was carried out 
at room temperature for 48 hours. The large panel that was produced was later cut into 6 rectangular plate specimens with dimensions $100 \mathrm{~mm} \times 150$ mmusing a CNC router machine as shown in Figure 2 and Figure 3. The total number of specimens fabricated and used for the impact tests isshown in Table 2.

Table 2: Total number of specimens

\begin{tabular}{|l|l|l|}
\hline Number of layers & $\begin{array}{l}\text { Type C-glass 600 } \\
\mathrm{g} / \mathrm{m}^{2}\end{array}$ & $\begin{array}{l}\text { Type E-glass 600 } \\
\mathrm{g} / \mathrm{m}^{2}\end{array}$ \\
\hline 10 layers & 12 & 12 \\
\hline 12 layers & 24 & 24 \\
\hline 14 layers & 24 & 24 \\
\hline
\end{tabular}

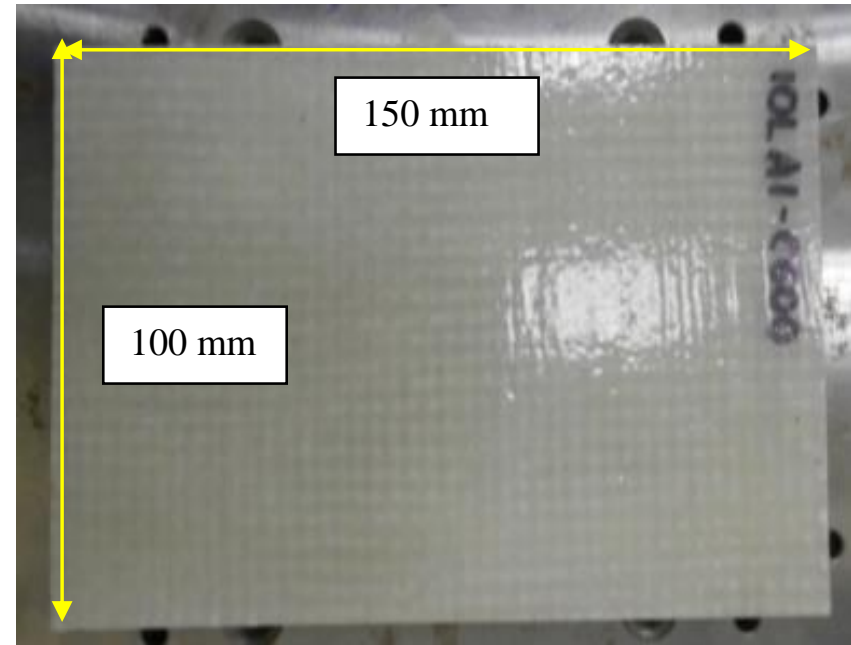

Fig2: Specimen with Dimensions $100 \mathrm{~mm} \times 150 \mathrm{~mm}$

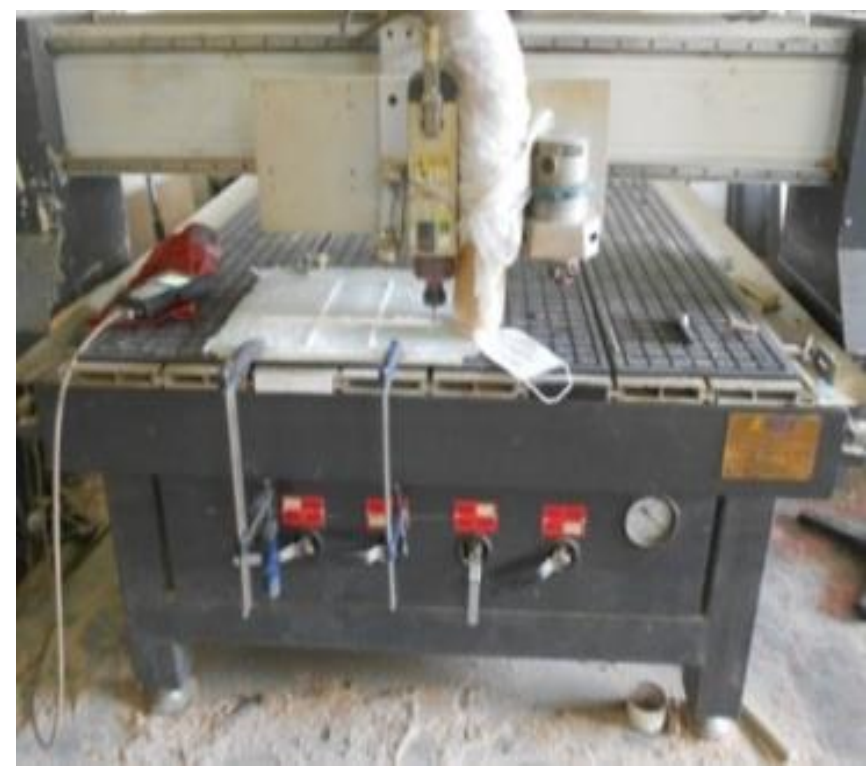

Fig 3: CNC Router Machine Model ACM 1325

\section{LOW VELOCITY TEST}

An IM10 Drop Weight Impact Tester was used to perform the tests as shown in Figure 4. The total drop weight impactor mass is $8.891 \mathrm{~kg}$ while the striker mass is $0.786 \mathrm{~kg}$. Figure 5 shows the $10 \mathrm{~mm}$ hemispherical cap that was used in this experiment. The specimens were clamped at the clamping unit under the drop mass so that it didnot move during the test. The impactor strikesthe centre of the specimen. The impact energy wasvaried at 7, 14, 21, 28, 35, 42, 49 and 56 Joule for 12 layer and 14 layer specimens. While for 10 layer specimens, the energy levels were varied at 14, 28, 42 and 56 Joule. This is due to a lack of material and it is not enough to produce more specimens for 10 layers. Varying the impact energy will vary the height of the drop mass as well as the velocity. The machine was set up to a single drop test with an anti-rebound mass. The data was then acquired usingImatek Impact Analysis software whichwas installed on the computer and connected to the IM10 Drop Weight Impact Tester. The energy absorbed by the specimens was calculated from the area under the graph of Force vs. Displacement using a MATLAB command.

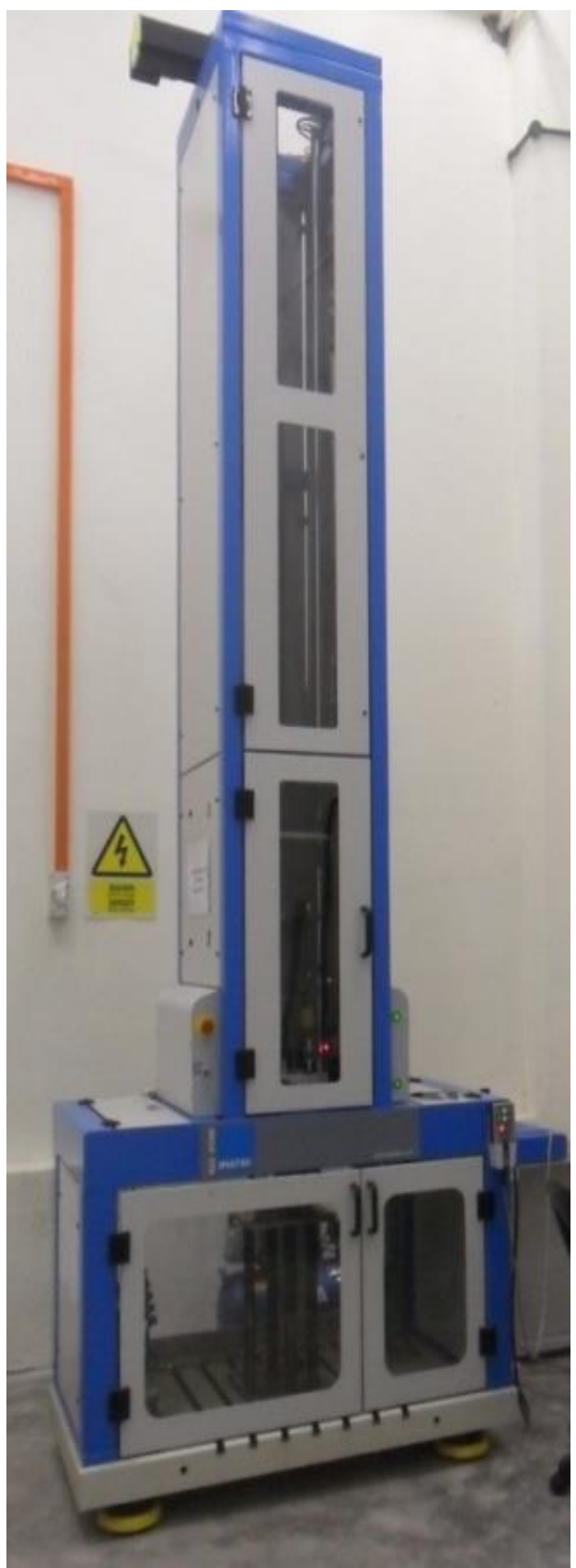

Fig 4: IM10 Drop Weight Impact Tester 


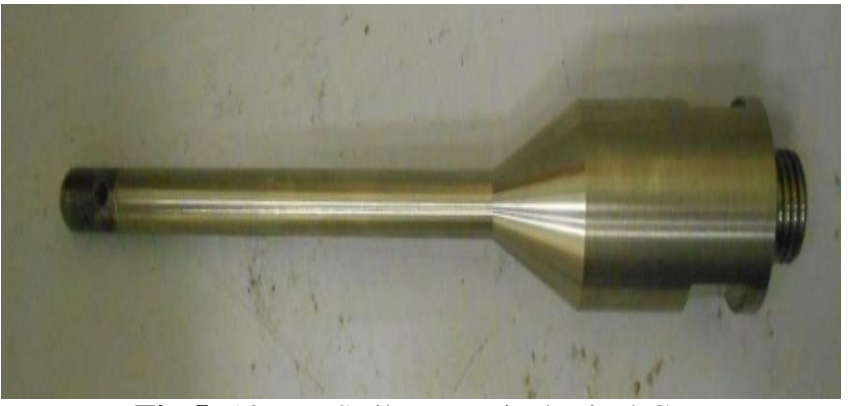

Fig 5: 10MM Striker Hemispherical Cap

\subsection{Non-Destructive Technique}

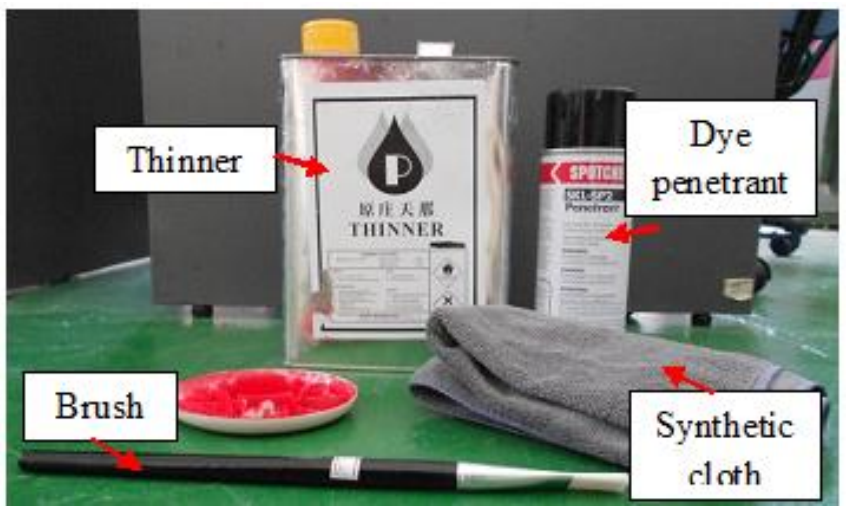

Fig 6: The apparatus for the dye penetrant process

There are many non-destructive techniquesthat can be used to examine the impact damage of composite materials. One of the non-destructive techniques is by using a dye penetrant process. Figure 6 shows the apparatus used for the dye penetrant process. Thinner was used to clean the surface of the specimens from small debris and dirt. A synthetic cloth was used to wipe the surface. Dye penetrant was applied on the surface of the test specimens and leftto dissipate through the damage area for 20 minutes. After 20 minutes, the specimens once again were wiped with a synthetic cloth and thinner to clean the surface. The damage area can be seen as the red colour of the dye contrasting with the colour of the specimens. As the damage areas are much clearer after using the dye penetrant, the area can then be calculated using grid paper and examined through the optical microscope.

\section{RESULTS AND DISCUSSION}

There were a total of 120 rectangular plate specimens used for the low velocity impact test. For each different impact energy level, 3 tests were conducted to check the repeatability. The reason for performing the repeatability test was to ensure that the impact force is behaving in a similar manner under the same impact condition. In this work, the variation of impact parameters - such as impact force, displacement, damage area, and energy absorbed versus impact energy - is examined in order to determinethe damage process on woven fabric composites in an impact event.The impact force can be defined as the response force of the specimens against the impactor. The impact energy is the initial potential energy from the impactor before the test. The energy absorbed by the specimens is the area under the force versus displacement graph.The damage area discussed in this paper is the damage area at the surface of the specimens calculated in a grid form by using oil paper and graph paper in order to reduce the error. The results from the low velocity impact test were obtained at the same test condition. The weight of the impactor is $8.891 \mathrm{~kg}$ and a 10 mm striker with a hemispherical cap was used for all test specimens. Table 3-8 shows the results that were collected in this experimental study.

Table 3: Results for 10 layer specimens Type C-glass/epoxy $600 \mathrm{~g} / \mathrm{m}^{2}$

\begin{tabular}{|l|l|l|l|l|l|}
\hline Impact energy (J) & Name & Peak force $(\mathrm{kN})$ & Peak Displacement $(\mathrm{mm})$ & Energy absorbed & Damage Area $\left(\mathrm{mm}^{2}\right)$ \\
\hline 14 & 10L B-C600 & 5.39 & 3.5167 & 8.6743 & 1617.667 \\
\hline 28 & 10L D-C600 & 7.5567 & 5.0767 & 18.5464 & 2922 \\
\hline 42 & 10L F-C600 & 8.3033 & 6.1 & 33.2622 & 3966 \\
\hline 56 & 10L H-C600 & 8.59 & 6.7333 & 48.0056 & 5034.667 \\
\hline
\end{tabular}

Table 4: Results for 12 layer specimens Type C-glass/epoxy $600 \mathrm{~g} / \mathrm{m}^{2}$

\begin{tabular}{|l|l|l|l|l|l|}
\hline Impact Energy $(\mathrm{J})$ & Name & Peak force $(\mathrm{kN})$ & Peak Displacement $(\mathrm{mm})$ & Energy absorbed & Damage Area $\left(\mathrm{mm}{ }^{2}\right)$ \\
\hline 7 & 12L A-C600 & 4.1567 & 2.38 & 3.6205 & 684 \\
\hline 14 & 12L B-C600 & 5.6933 & 3.2433 & 8.6471 & 1405.333 \\
\hline 21 & 12L C-C600 & 7.3833 & 4.1533 & 12.2356 & 1620 \\
\hline 28 & 12L D-C600 & 8.4933 & 4.59 & 17.6694 & 2095.333 \\
\hline 35 & 12L E-C600 & 9.3467 & 5.2033 & 23.6213 & 2308 \\
\hline 42 & 12L F-C600 & 9.4767 & 5.6133 & 30.5003 & 3134.667 \\
\hline 49 & 12L G-C600 & 10.0867 & 6.0967 & 35.5655 & 3793.333 \\
\hline 56 & 12L H-C600 & 10.1033 & 7.1367 & 46.5123 & 4257.333 \\
\hline
\end{tabular}


Table 5: Results for 14 layer specimens Type C-glass/epoxy $600 \mathrm{~g} / \mathrm{m}^{2}$

\begin{tabular}{|l|l|l|l|l|l|}
\hline Imapct Energy $(\mathrm{J})$ & Name & Peak force $(\mathrm{kN})$ & Peak Displacement $(\mathrm{mm})$ & Energy absorbed & Damage Area $\left(\mathrm{mm}{ }^{2}\right)$ \\
\hline 7 & 14L A-C600 & 5.26 & 1.7033 & 3.7325 & 246.6667 \\
\hline 14 & 14L B-C600 & 6.67 & 2.58 & 8.7247 & 708 \\
\hline 21 & 14L C-C600 & 7.6467 & 3.8767 & 13.0042 & 1668 \\
\hline 28 & 14L D-C600 & 9.1667 & 4.2567 & 18.7418 & 1901.333 \\
\hline 35 & 14L E-C600 & 10.5 & 4.6867 & 23.4823 & 2215.333 \\
\hline 42 & 14L F-C600 & 10.9167 & 5.6067 & 28.3653 & 2898.667 \\
\hline 49 & 14L G-C600 & 11.0867 & 6.1533 & 34.6377 & 3497.333 \\
\hline 56 & 14L H-C600 & 11.47 & 6.5467 & 42.1253 & 4260.667 \\
\hline
\end{tabular}

Table 6: Results for 10 layer specimens Type E-glass/epoxy $600 \mathrm{~g} / \mathrm{m}^{2}$

\begin{tabular}{|l|l|l|l|l|l|}
\hline Imapct Energy (J) & Name & Peak force $(\mathrm{kN})$ & Peak Displacement (mm) & Energy Absorbed & Damage Area (mm $\left.{ }^{2}\right)$ \\
\hline 14 & & & & & 3.23 \\
\hline 28 & 10L B-E600 & 5.79 & 3.5833 & 15.9324 & 956 \\
\hline 42 & 10L F-E600 & 9.37 & 5.1533 & 26.6663 & 1428.667 \\
\hline 56 & 10L H-E600 & 9.9033 & 7.9133 & 42.5102 & 1731.333 \\
\hline
\end{tabular}

Table 7: Results for 12 layer specimens Type E-glass/epoxy $600 \mathrm{~g} / \mathrm{m}^{2}$

\begin{tabular}{|c|c|c|c|c|c|}
\hline Imapct Energy (J) & Name & Peak force $(\mathrm{kN})$ & Peak Displacement (mm) & Energy Absorbed & Damage Area $\left(\mathrm{mm}^{2}\right)$ \\
\hline 7 & 12L A-E600 & 4.76 & 2.0767 & 3.421 & 101.3333 \\
\hline 14 & 12L B-E600 & 6.46 & 3.0867 & 7.3264 & 358.6667 \\
\hline 21 & 12L C-E600 & 7.7833 & 3.9 & 11.8612 & 685.3333 \\
\hline 28 & 12L D-E600 & 9.2233 & 4.4933 & 16.8106 & 978.6667 \\
\hline 35 & 12L E-E600 & 10.4433 & 5.5233 & 19.3491 & 1545.333 \\
\hline 42 & 12L F-E600 & 11.3167 & 5.8667 & 24.3216 & 1593.333 \\
\hline 49 & 12L G-E600 & 12.1167 & 6.3767 & 28.771 & 1980 \\
\hline 56 & 12L H-E600 & 13.07 & 6.7067 & 33.775 & 2217.333 \\
\hline
\end{tabular}

Table 8: Results for 14 layer specimens Type E-glass/epoxy $600 \mathrm{~g} / \mathrm{m}^{2}$

\begin{tabular}{|l|l|l|l|l|l|}
\hline Imapct Energy (J) & Name & Peak force $(\mathrm{kN})$ & Peak Displacement (mm) & Energy Absorbed & Damage Area (mm $\left.{ }^{2}\right)$ \\
\hline 7 & & & & & \\
\hline 14 & 14L A-E600 & 5.8533 & 1.39 & 4.5988 & 77.3333 \\
\hline 21 & 14L B-E600 & 7.85 & 2.0867 & 9.2981 & 129.3333 \\
\hline 28 & 14L C-E600 & 9.64 & 2.7633 & 12.5535 & 206.6667 \\
\hline 35 & 14L D-E600 & 11.04 & 3.3967 & 16.1443 & 237.3333 \\
\hline 42 & 14L E-E600 & 11.8767 & 4.3467 & 20.6026 & 898 \\
\hline 49 & 14L F-E600 & 12.9867 & 5.07 & 24.736 & 912 \\
\hline 56 & 14L G-E600 & 13.98 & 5.2967 & 29.6575 & 1117.333 \\
\hline
\end{tabular}


A graph has been drawn and the overall results of the test are presented in the Figure below.

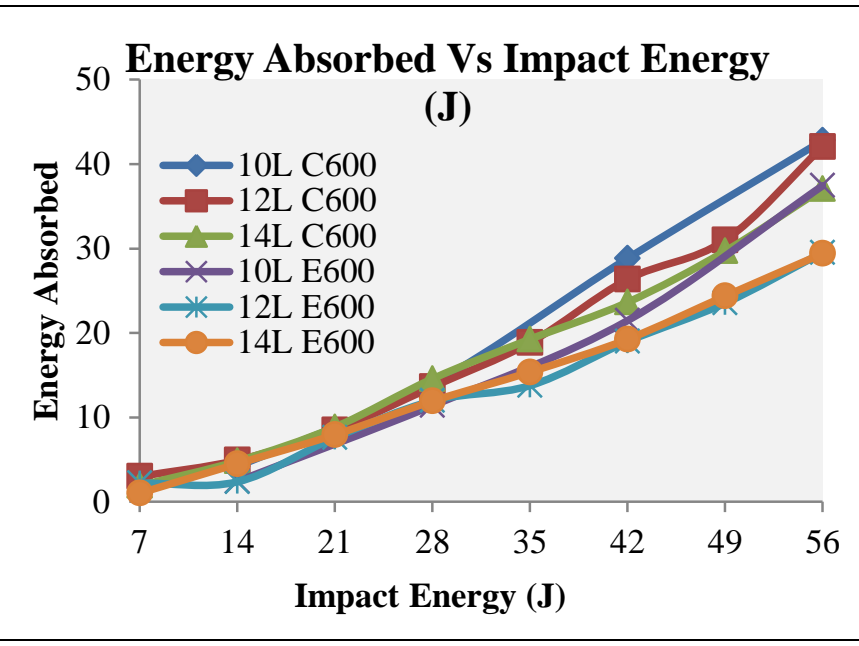

Fig 7: Graph of Average Energy Absorbed versus Impact Energy

Figure 7 illustrates the energy absorbed versus the impact energy for both types of GFRP for specimens of 10 layers, 12 layers and 14 layers. The energy absorbed was calculated from the area under the graph of Impact Force versus Displacement as illustrated in Figure 17 and Figure 18.The energy absorbed can be defined byEquation 2 .

$$
\text { Energy absorbed by the specimens, } E=\int F V d t
$$

From the graph, 10 layer specimens have absorbed higher energy than 12 layer and 14 layer specimens. As thenumbers of layers of GFRP increases, the energy that can be absorbed by the specimens decreases. When the impact energy increases, the energy absorbed also increases. From this graph, Type C-glass/epoxy $600 \mathrm{~g} / \mathrm{m}^{2}$ has absorbed a higher energy compared toType E-glass/epoxy $600 \mathrm{~g} / \mathrm{m}^{2}$.

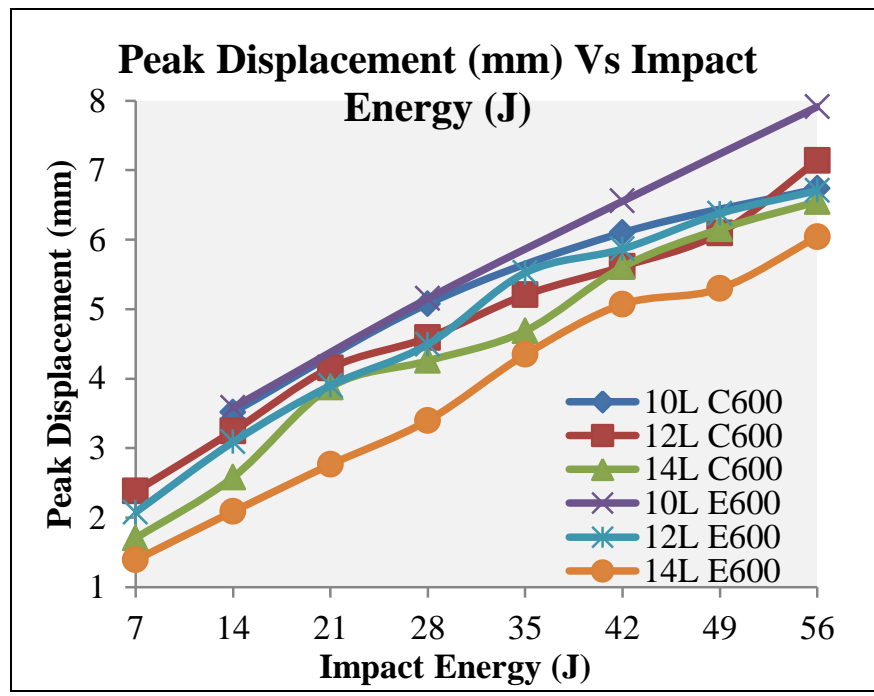

Fig 8: Graph of Peak Displacement versus Impact Energy

Figure 8 illustrates the relation between peak displacement and impact energy. From this graph, as the impact energy increases, the values of peak displacement also increase. It has a similar linear trend for all layers and types of specimens. 10 layers have the highest peak displacement followed by 12 layers and 14 layers for both types. Type Cglass/epoxy $600 \mathrm{~g} / \mathrm{m}^{2}$ hasa higher peak displacement compared to Type E-glass/epoxy $600 \mathrm{~g} / \mathrm{m}^{2}$.

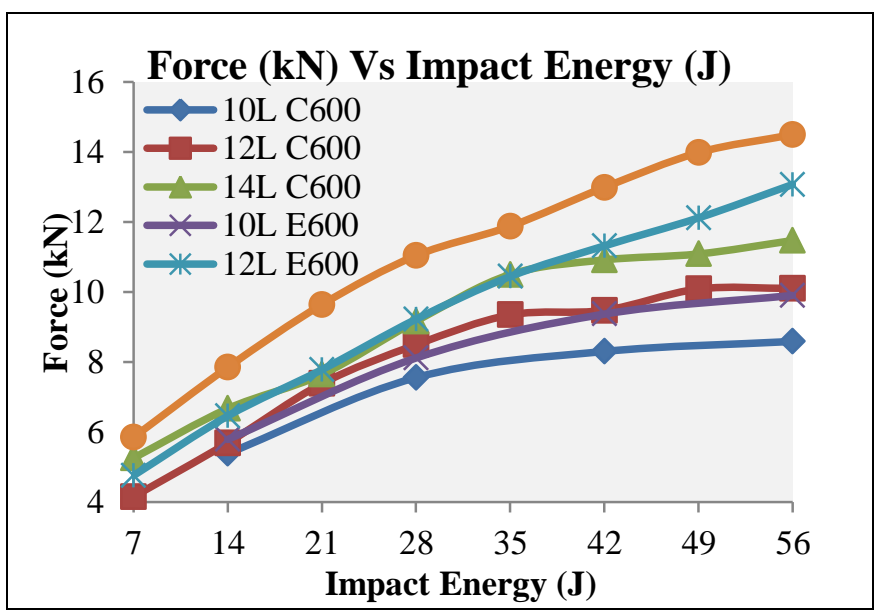

Fig 9: Graph of Impact Force versus Impact Energy

Figure 9 illustrates the relationship between impact force and impact energy. From this graph, as the impact energy increases, the impact force also increases. Again, it has a similar linear trend for all layers and types of specimens. 14 layers have the highest impact force followed by 12 layers and 10 layers for both types. Type E-glass/epoxy 600 $\mathrm{g} / \mathrm{m}^{2}$ hasa higher impact force compared to Type Cglass/epoxy $600 \mathrm{~g} / \mathrm{m}^{2}$.

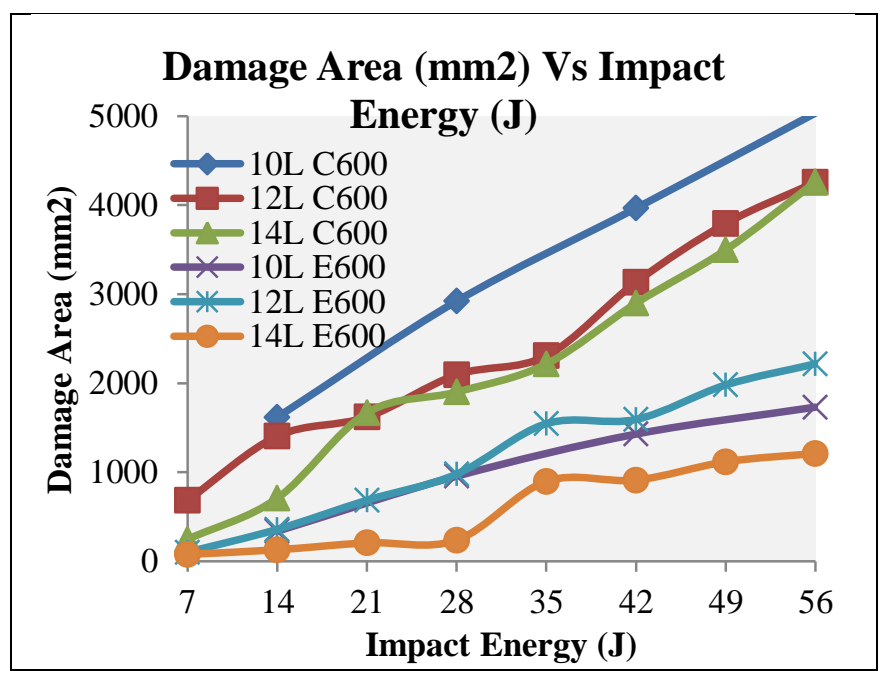

Fig 10: Graph of Damage Area versus Impact Energy

Figure 10 illustrates the damage area versus impact energy for both types of GFRP, for 10 layer, 12 layer and 14 layer specimens. From the graph, 10 layer specimens have a higher damage area than 12 layer and 14 layer specimens. More damage occurs when the specimens aremuch thinner. As the impact energy increases, the damage area also increases. The trend of damage area can be observed in the Figure below. From this graph, Type C-glass/epoxy 600 
$\mathrm{g} / \mathrm{m}^{2}$ hasahigher damage area compared toType Eglass/epoxy $600 \mathrm{~g} / \mathrm{m}^{2}$.

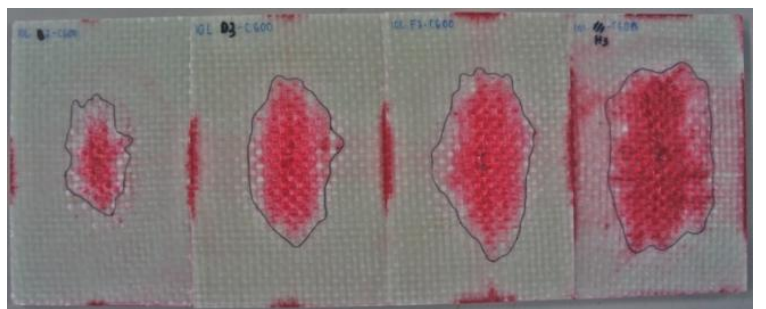

Fig 11: Specimens of 10 layers of Type C-glass/epoxy 600 $\mathrm{g} / \mathrm{m}^{2}$ from impact energy $14,28,42$, and $56 \mathrm{~J}$

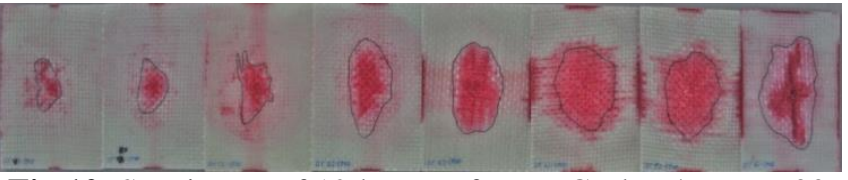

Fig 12: Specimens of 12 layers of Type C-glass/epoxy 600 $\mathrm{g} / \mathrm{m}^{2}$ from impact energy $7,14,21,28,35,42,49$, and $56 \mathrm{~J}$

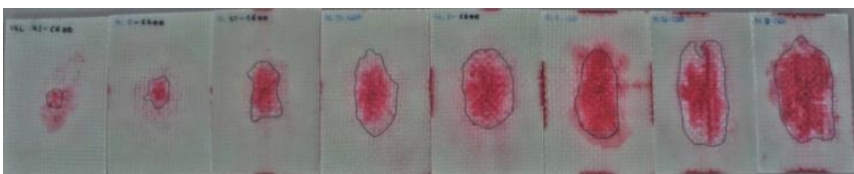

Fig 13: Specimens of 14 layers of Type C-glass/epoxy 600 $\mathrm{g} / \mathrm{m}^{2}$ from impact energy $7,14,21,28,35,42,49$, and $56 \mathrm{~J}$

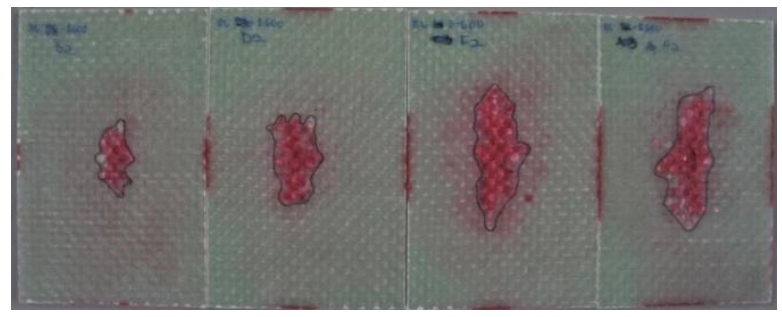

Fig 14: Specimens of 10 layers of Type E-glass/epoxy 600 $\mathrm{g} / \mathrm{m}^{2}$ from impact energy $14,28,42,56 \mathrm{~J}$

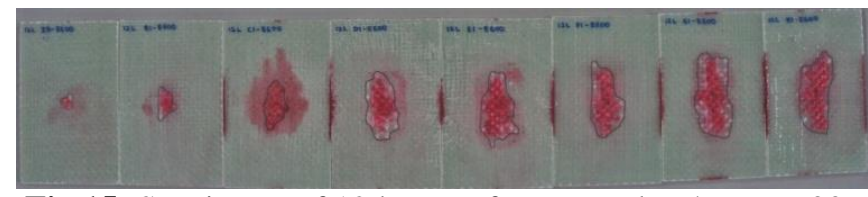

Fig 15: Specimens of 12 layers of Type E-glass/epoxy 600 $\mathrm{g} / \mathrm{m}^{2}$ from impact energy $7,14,21,28,35,42,49$, and $56 \mathrm{~J}$

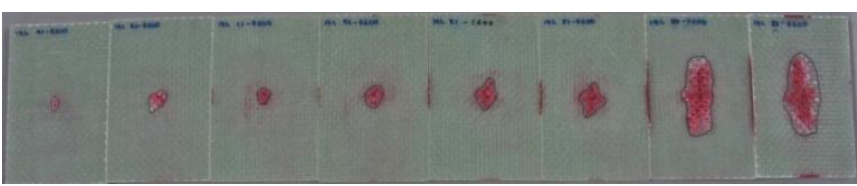

Fig 16: Specimens of 14 layers of Type E-glass/epoxy 600 $\mathrm{g} / \mathrm{m}^{2}$ from impact energy $7,14,21,28,35,42,49$, and $56 \mathrm{~J}$

Images of the damage surfaces of the plate are illustrated in Figures11-16. From observation of the pictures obtained, beyond the area and damage lengths, Type C-glass/epoxy $600 \mathrm{~g} / \mathrm{m}^{2}$ sustainsawider damage area compared to Type Eglass/epoxy $600 \mathrm{~g} / \mathrm{m}^{2}$. The damage area tends towards an approximately circular form for Type C-glass/epoxy 600 $\mathrm{g} / \mathrm{m}^{2}$ and a long oval form for Type E-glass/epoxy 600 $\mathrm{g} / \mathrm{m}^{2}$ as the number of layers increases. Some of the specimens tend to form a "four leaf clover" damage area. It can be observed that Type C-glass/epoxy $600 \mathrm{~g} / \mathrm{m}^{2}$ experienced more damage than Type E-glass/epoxy 600 $\mathrm{g} / \mathrm{m}^{2}$ based on the damage area created.

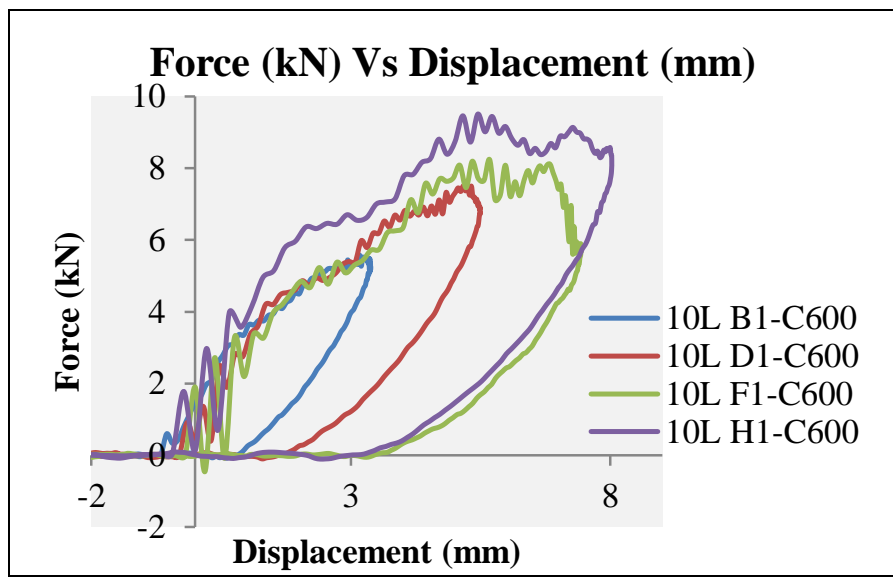

(a)

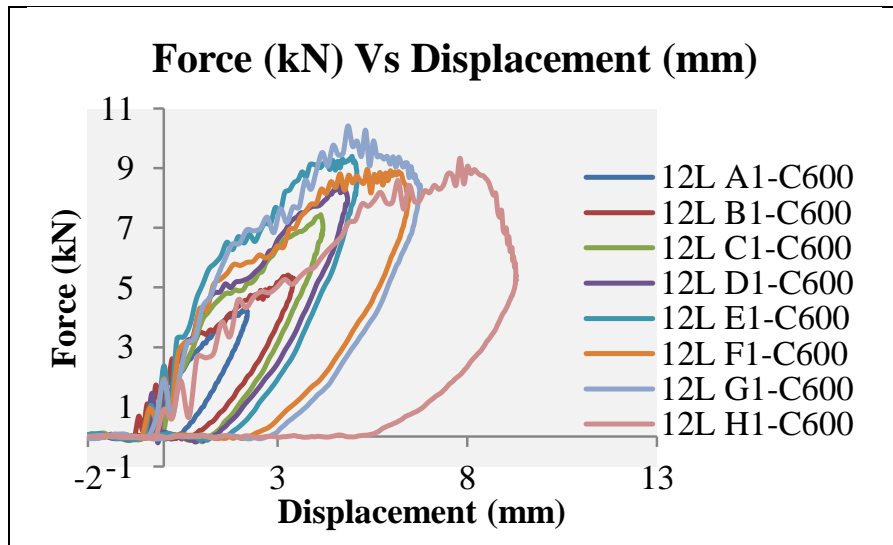

(b)

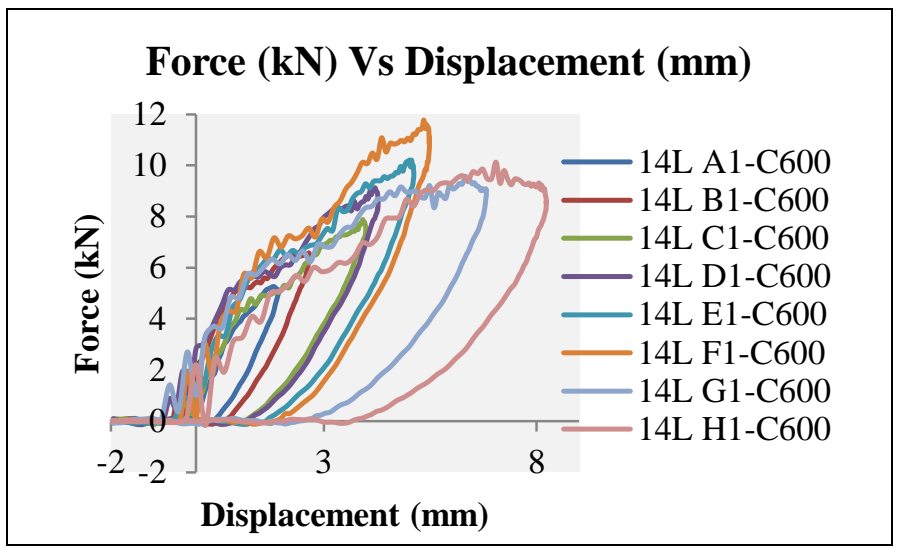

(c)

Fig 17: Graph of Impact Force versus Displacement of Type C-glass/epoxy $600 \mathrm{~g} / \mathrm{m}^{2}$ for (a) 10 layers, (b) 12 layers, and (c) 14 layers

Figure 17 illustrates the impact force versus displacement graph for: 17 (a) 10 layers, 17 (b) 12 layers, and 17 (c) 14 layers of type C-glass/epoxy $600 \mathrm{~g} / \mathrm{m}^{2}$. This graph was used 
to calculatethe energy absorbed by the specimens which was the area under the graph. From the graph, the highest impact energy is the $\mathrm{H} 1$ specimens; theyhaveabsorbed more energy compared to the others because theyhavea bigger closed loop. A1 specimens have the lowest absorbed energy since the closed looped of this graph is much smaller.

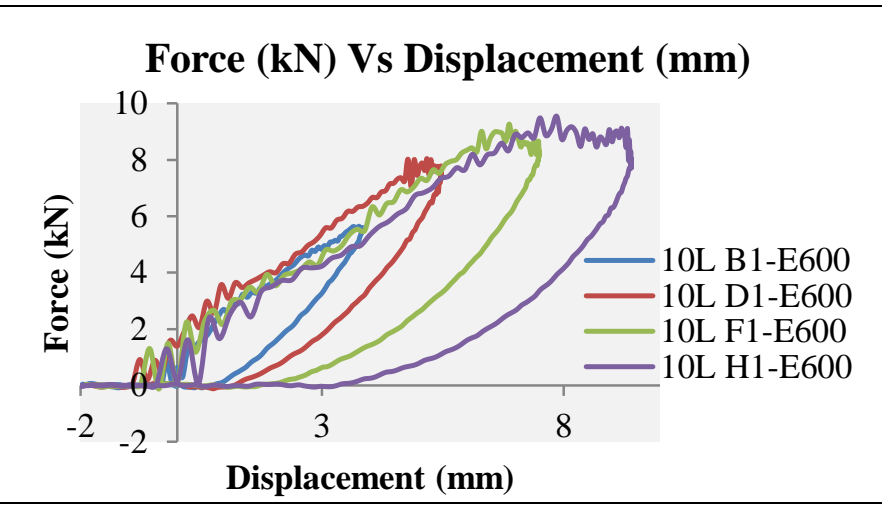

(a)

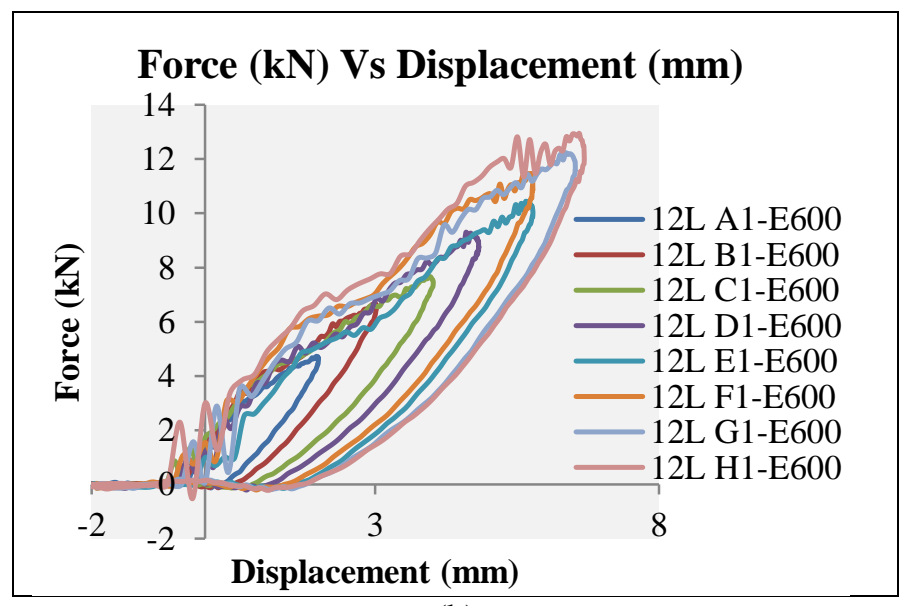

(b)

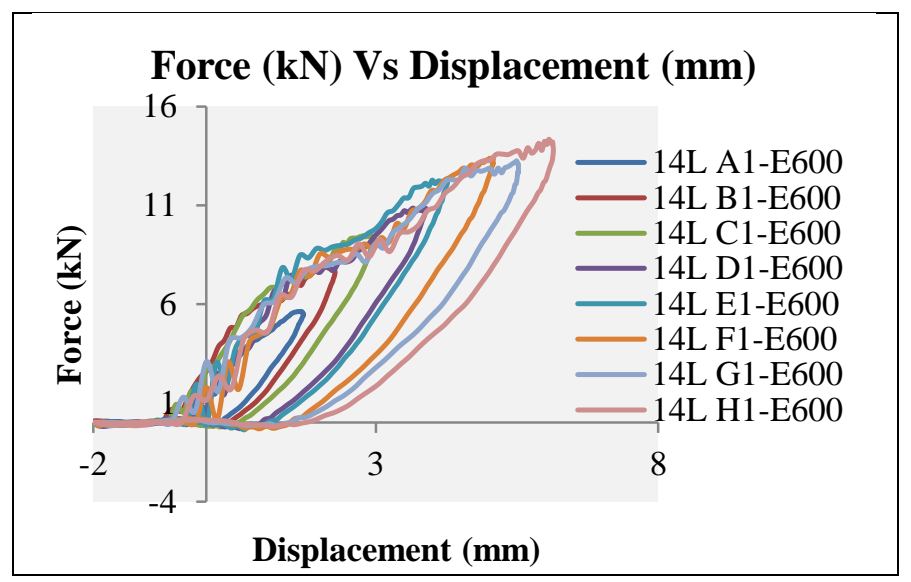

(c)

Fig18: Graph of Impact Force versus Displacement of Type E-glass/epoxy $600 \mathrm{~g} / \mathrm{m}^{2}$ for (a) 10 layers, (b) 12 layers, and (c) 14 layers

Figure 18 illustrates the impact force versus displacement graph for: 18 (a) 10 layers, 18 (b) 12 layers, and 18 (c) 14 layers of type E-glass/epoxy $600 \mathrm{~g} / \mathrm{m}^{2}$. All graphs for all energy levelshavea similar closed, looped pattern. Again, this graph was used to calculatethe energy absorbed by the specimens which was the area under the graph. From the graph, the highest impact energy is the H1 specimens;they haveabsorbed more energy compared to the others because they havea bigger closed loop. A1 specimens have the lowest absorbed energy since the closed loop of this graph is much smaller.

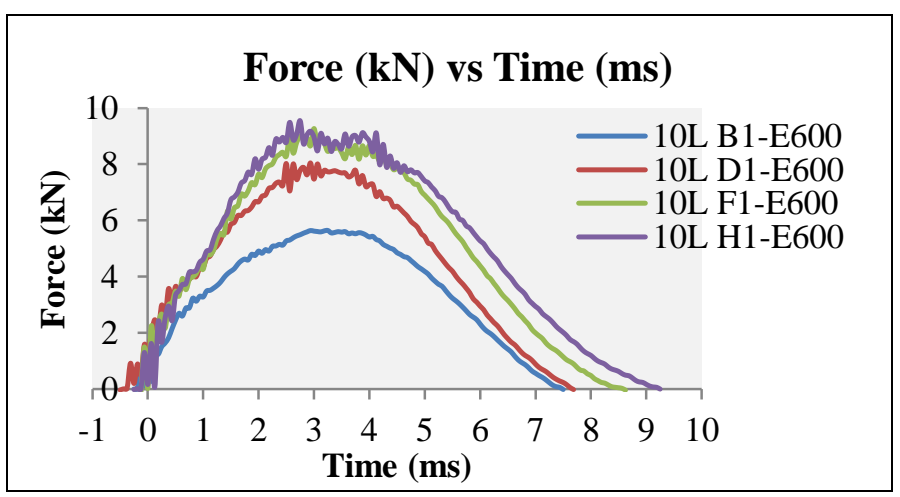

(a)

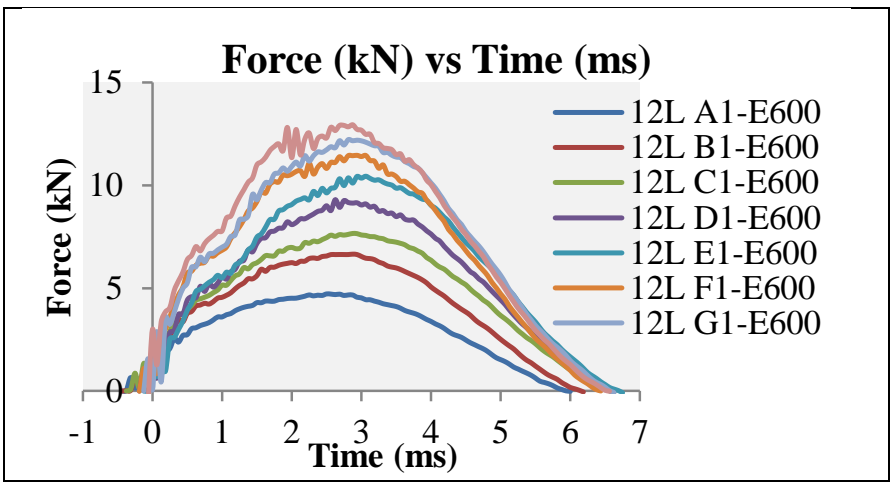

(b)

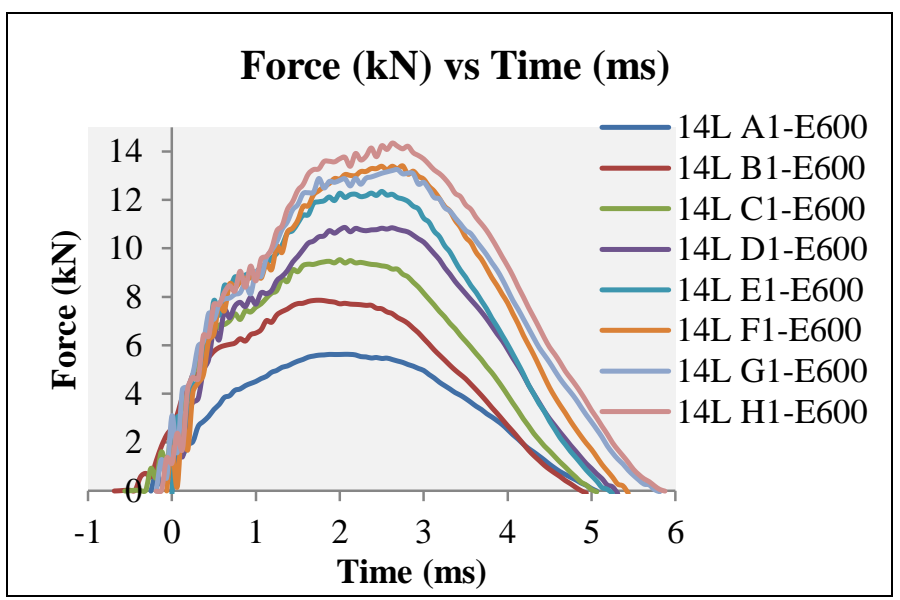

(c)

Fig 19: Graph of Impact Force versus Time of Type Eglass/epoxy $600 \mathrm{~g} / \mathrm{m}^{2}$ for (a) 10 layers, (b) 12 layers, and (c) 14 layers

Figure 19 shows the force-time graph for Type Eglass/epoxy $600 \mathrm{~g} / \mathrm{m}^{2}$ with different impact energy levels 
which form the lowest impact energy (A1) to the highest impact energy (H1). Figure 19(a) shows the result for 10 layer specimens, which only have 4 tests at different energy levels. Figure 19 (b) shows the result for 12 layers and Figure 19(c) shows the results for 14 layer specimens. From the graph, it can be observed that as the impact energy increases the impact force also increases. From a comparison between the three graphs, the 14 layerspecimens had the highest impact force, which is almost $14 \mathrm{kN}$, when subjected to 56 Joule of impact energy (H1) compared to 12 layer specimens and 10 layer specimens.

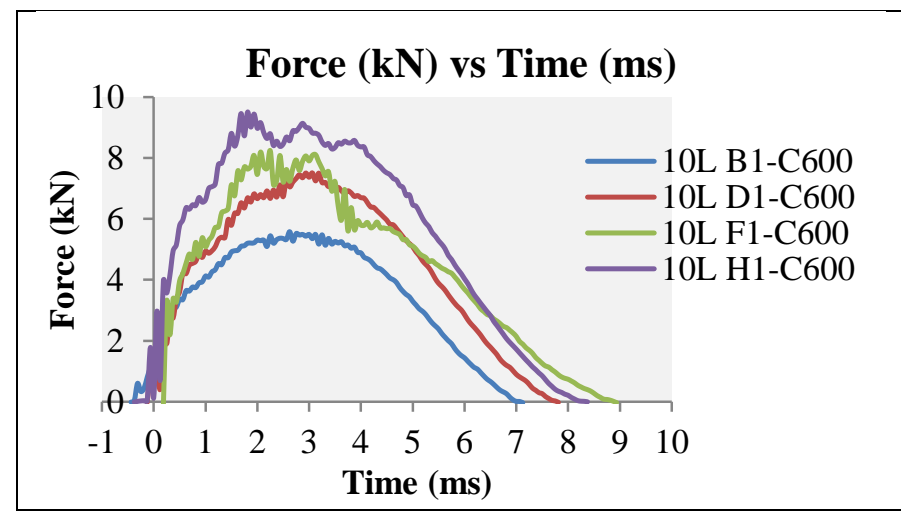

(a)

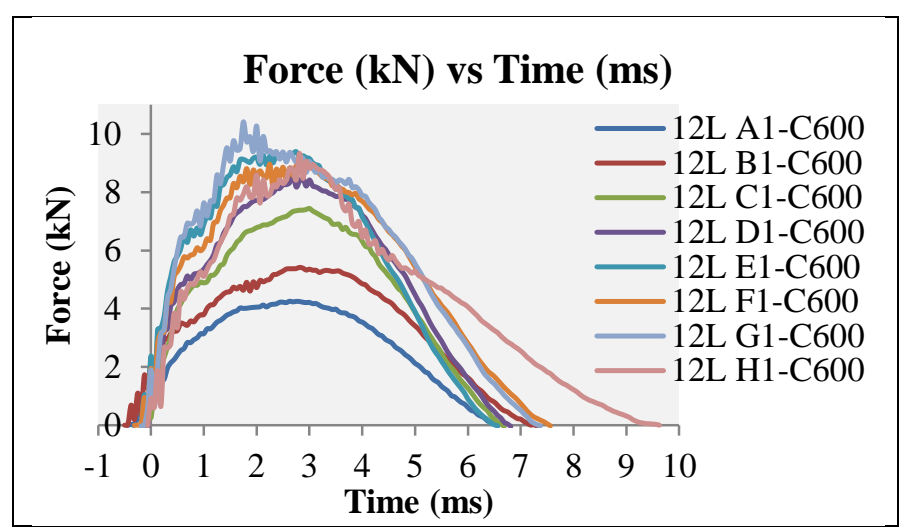

(b)

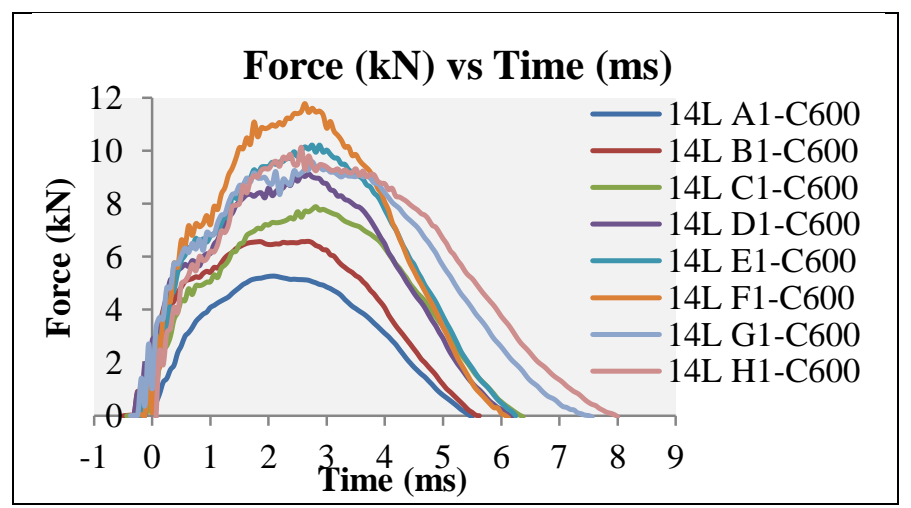

(c)

Type E-glass/epoxy $600 \mathrm{~g} / \mathrm{m}^{2}$. Figure 20 (a) is the results for 10 layers, 20 (b) for 12 layers and 20 (c) for 14 layers. From this graph, it can also be seen that as the impact energy increases, the impact force also increases. The increase of impact energy will increase the height of the impactor and resultsin increases of the drop velocity as well as the impact force.

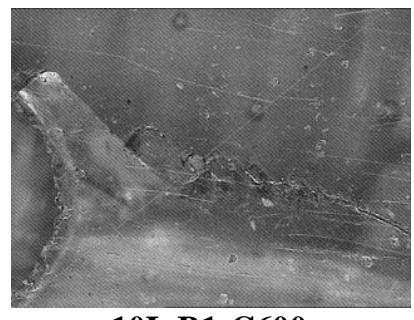

10L B1-C600

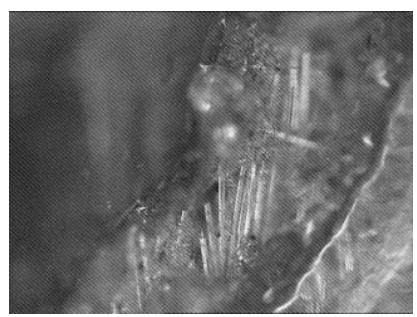

10L F1-C600

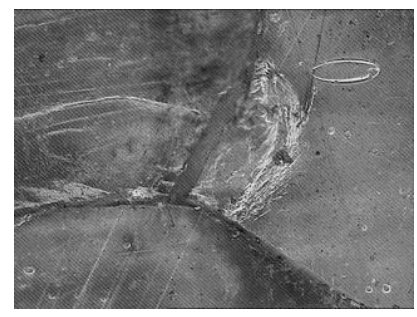

10L D1-C600

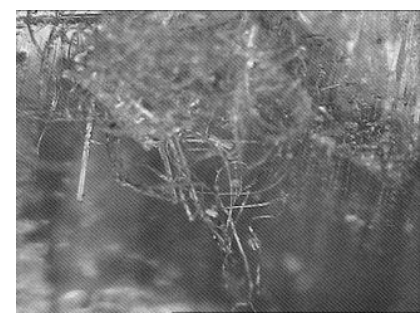

10L H1-C600

Fig 21: Microscope images of the specimens for 10 layer specimens under different impact energy levels.

Figure 21 shows the microscope images of 10 layer specimens under 5 times magnification for impact energy 14 $\mathrm{J}$ (B1), $28 \mathrm{~J}$ (D1), $42 \mathrm{~J}$ (F1) and $56 \mathrm{~J}$ (H1). From the figures can be seen the type of damage occurring for each specimen. For the lowest impact energy, which is B1 specimens, only delamination and matrix cracking occurs. No fibres are seen in this figure. For D1 specimens, which are at $28 \mathrm{~J}$ impact energy, the crack is much wider than for B1 specimens. At these energy levels, delamination still occurs and the fibre is starting to crack. At impact energy $42 \mathrm{~J}$, which is F1 specimens, the fibres are seen which means the damage is much deeper. From the figures, it can be seen that the fibres are fractured. Lastly, for the highest impact energy, which is $56 \mathrm{~J}$ (H1), the fibres that are already fractured are breaking and pulling out from their original position.

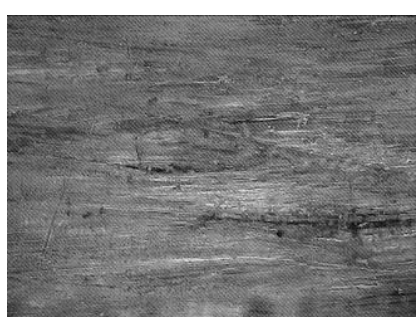

12L A1-C600

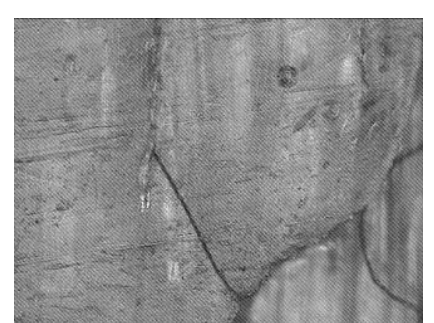

12L B1-C600

Fig 20: Graph of Impact Force versus Time of Type Cglass/epoxy $600 \mathrm{~g} / \mathrm{m}^{2}$ for (a) 10 layers, (b) 12 layers, and (c) 14 layers

Figure 20 shows the result of force-time for Type Cglass/epoxy $600 \mathrm{~g} / \mathrm{m}^{2}$. It shows the same pattern of curve as 


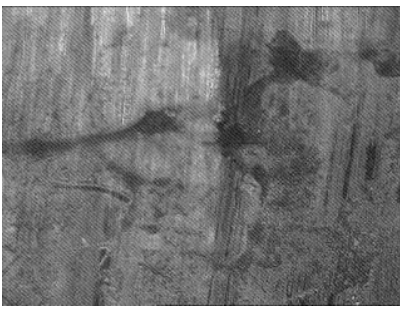

12L C1-C600

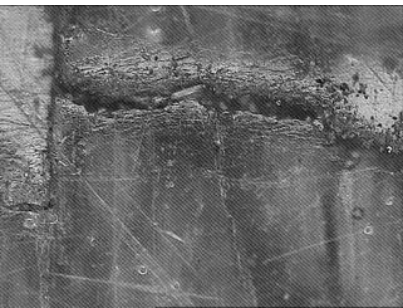

12L E1-C600

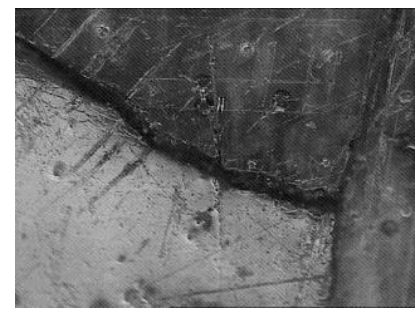

12L G1-C600

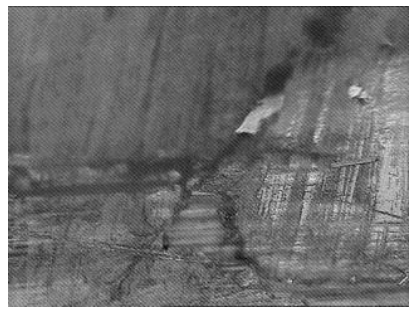

12L D1-C600

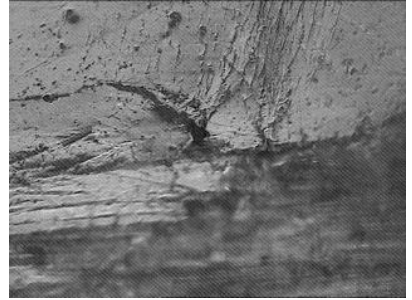

12L F1-C600

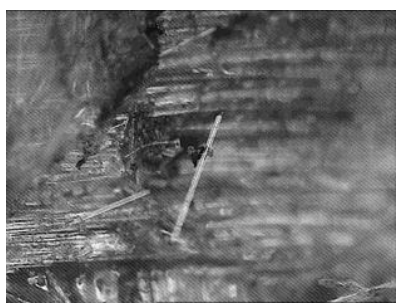

12L H1-C600
Fig 22: Microscope images of the specimens under 5 times magnification for 12 layer specimens from impact energy 7 $\mathrm{J}$ (A1) to $56 \mathrm{~J}$ (H1).

Figure 22 shows the microscope images for 12 layer specimens. Again, the type of damage which occurs is also wider as the impact energy increases. It startsto form delamination, matrix cracking, fibre cracking, fibre fracture, matrix breakage, fibre breakage and finally the fibre will pull out. Type E-glass/epoxy $600 \mathrm{~g} / \mathrm{m}^{2}$ also has the same failure as Type C-glass/epoxy $600 \mathrm{~g} / \mathrm{m}^{2}$, the only difference is that Type $\mathrm{C}$ experienced much larger and wider crack/ damage than Type E. All images show the same condition at the same energy levels. The observation of the damage can be concluded in Table 9 below.

Table 9: Observation of Damage for Test Specimen

\begin{tabular}{|c|c|}
\hline $\begin{array}{l}\text { Impact } \\
\text { Energy level }\end{array}$ & Type of failure \\
\hline 7 & Matrix cracking \\
\hline 14 & Delamination \\
\hline 21 & Fibre cracking \\
\hline 28 & $\begin{array}{ll}- & \text { Matrix cracking } \\
- & \text { Delamination }\end{array}$ \\
\hline 35 & Fibre fracture \\
\hline 42 & Matrix cracking \\
\hline 49 & Delamination \\
\hline 56 & $\begin{array}{ll}- & \text { Fibre breakage } \\
- & \text { Fibre pullout } \\
- & \text { Matrix breakage }\end{array}$ \\
\hline
\end{tabular}

\section{SUMMARY}

Anexperimental investigation examining changes in the test specimens' number of layers and impact energy levelsusing an IM10 Drop Weight Impact Tester under low velocity impact - has been conducted. The impact force, impact energy, energy absorbed, damage area, displacement and the effect of low velocity impact corresponding to different numbers of layers and impact energy levelsbetween two types of fibreglass- Type C-glass/Epoxy $600 \mathrm{~g} / \mathrm{m}^{2}$ and Type E-glass/Epoxy $600 \mathrm{~g} / \mathrm{m}^{2}$ - have been examined. The impactor exhibited a condition of single drop with anti-rebound on the specimens, when subjected to impact at different energy levels. The impact force versus impact energy, displacement versus impact energy, damage area versus impact energy and the energy absorbed versus impact energy curves for each type of composite laminate plates have been drawn on the same graph showing an impressive pattern. C-type absorbed more impact energy than E-type GFRP. C-type experienced more damage as the energy absorbed was much higher and the damage areas weregreater than E-type. A non-destructive technique has been used to observe the type of failure ofthe two types of fibreglass. The damage mechanisms that the composite laminates face in this study of low velocity impact are delamination, matrix cracking, matrix breakage, fibre cracking, fibre breakage, and fibre pullout.

\section{ACKNOWLEDGEMENTS}

This work is supported by UPM under GP-IPB grant, 9415402.

\section{REFERENCES}

[1] D.A. Bond. "Composites". MSc Lecture Notes. School of Mechanical, Aerospace and Civil Engineering, University of Manchester.

[2] N. Yidris, R. Zahari, D.L. Majid, F. Mustapha, M.T.H. Sultan and A.S.M. Rafie. "Crush Simulation of Woven C-Glass/Epoxy Unmanned Ariel Vehicle Fuselage Section". International Journal of Mechanical and Material Engineering, (2010), Vol. 5(2), 260-267.

[3] M.T.H. Sultan. "Impact Damage Characterisation in Composite Laminates". PhD Thesis, Department of Mechanical Engineering the University of Sheffield, (2011).

[4] M.T.H. Sultan, K. Worden, W.J. Staszewski and A. Hodzic. "Impact damage characterisation of composite laminates using a statistical approach". Composites Science and Technology, 72 (2012)(10) 1108-1120.

[5] A. Vlot and JW. Gunnink. "Fibre metal laminates, an introduction". Dordrecht, the Netherlands: Kluwer Academic Publishers (2001).

[6] G.A. Schoeppner and S. Abrate. "Delamination threshold loads for low velocity impact on composite laminates". Composite Part A: Applied Science and Manufacturing, (2000), 31(9), 903-915. 
[7] M.T.H. Sultan, F. Mustapha, A.S.M. Rafie, D.L. Majid and R. Ajir. "Impact Damage Detection and Quantification for CFRP Laminates Subjected To Low Velocity Impact Damage - A NDT Approach". Journal of Malaysian Society for Non-Destructive Testing (NDT Spectra), (2011), 5, 15-20.

[8] N.K. Naik, Y.S. Chandra, and S. Meduri. "Damage in woven-fabric composites subjected to low-velocity impact". Composite Science and Technology, (2000), 60(5), 731-744.

[9] N.F. Rilo, and L.M.S. Ferreira. "Experimental study of low-velocity impacts on glass-epoxy laminated composite plates". Int J Mech Mater Des, (2008) DOI 10.1007/s10999-008-9071-5.

[10] V. Tita, J.D. Carvalho, and D. Vandepitte. "Failure analysis of low velocity impact on thin composite laminates: Experimental and numerical approaches". Composite Structures 83 (2008) 413-428

[11] D.E. Grady, N.A. Winfree. "Impact fragmentation of high-velocity compactprojectiles on thin plates: a physical and statistical characterization offragment debris". Int J Impact Eng 2001;26(1-10):249-62.

[12] RC. Hibbler. "Engineering mechanics: statistics". 5th ed. New York: Macmillan (1989).

[13] M.T.H. Sultan, K. Worden, W.J. Staszewski, A. Hodzic. "Impact damage characterisation of composite laminates using a statistical approach". Composites Science and Technology 72 (2012) 1108-1120.

[14] N. Rajesh Mathivanan, and J. Jerald. "Experimental investigation of low-velocity impact characteristics of woven glass fiber epoxy matrix composite laminates of EP3 grade". Materials and Design 31 (2010) 45534560 .

[15] Z.Y. Zhang, M.O.W. Richardson. "Low velocity impact induced damage evaluation and its effect on the residual flexural properties of pultruded GRP composites". Compos Struct (2007), 81:195-201.

[16] S. Abrate. "Impact on composite structures". London: Cambridge University Press; 1998

[17] M.J. Santos, J.B. Santos, A.M. Amaro,and M.A. Neto. "Low velocity impact damage evaluation in fiber glass composite plates using PZT sensors". Composites: Part B 55 (2013) 269-276.

[18] S. Sfarra, C.I. Castanedo, C. Santulli, A. Paoletti, D. Paoletti, F. Sarasini, A. Bendada, X. Maldague. "Falling weight impacted glass and basalt fibre woven composites inspected using non-destructive techniques". Composites: Part B 45 (2013) 601-608.

[19] P. Russo, D. Acierno, G. Simeoli, S. Iannace, L. Sorrentino. "Flexural and impact response of woven glass fiber fabric/polypropylene composites". Composites: Part B 54 (2013) 415-421.

[20] F. Sarasini, J. Tirillò, M. Valente, T. Valente, S. Cioffi, S. Iannace, L. Sorrentino. "Effect of basalt fiber hybridization on the impact behavior under low impact velocity of glass/basalt woven fabric/epoxy resin composites". Composites: Part A 47 (2013) 109-123.
[21] Z. Mouti, K. Westwood, D. Long, J. Njuguna. “An experimental investigation into localised low-velocity impact loading on glass fibre-reinforced polyamide automotive product". Composite Structures 104 (2013) 43-53.

[22] N.S. Choi, J.Y. Chang, S.B. Kwak, J.U. Gu. "Impact surface fractures of glass-fiber/epoxy lamina-coated glass plates by small steel-ball". Composites Science and Technology 70 (2010) 2056-2062.

[23] G. Reyes, and U. Sharma. "Modeling and damage repair of woven thermoplastic composites subjected to low velocity impact". Composite Structures 92 (2010) 523-531.

[24] C. Atas, Y. Akgun, O. Dagdelen, B. M. Icten, M. Sarikanat. "An experimental investigation on the low velocity impact response of composite plates repaired by VARIM and hand lay-up processes". Composite Structures 93 (2011) 1178-1186.

[25] G. Caprino, V. Lopresto, A. Langella, M. Durante. "Irreversibly absorbed energy and damage in GFRP laminates impacted at low velocity". Composite Structures 93 (2011) 2853-2860.

[26] I.H. Choi, I.G. Kim, S.M. Ahn, C.H. Yeom. "Analytical and experimental studies on the lowvelocity impact response and damage of composite laminates under in-plane loads with structural damping effects". Composites Science and Technology 70 (2010) 1513-1522.

[27] S. Zainuddin, T. Arefin, A. Fahim, M.V. Hosur, J.D. Tyson, Ashok Kumar, J. Trovillion, and S. Jeelani. "Recovery and improvement in low-velocity impact properties of e-glass/epoxy composites through novel self-healing technique". Composite Structures 108 (2014) 277-286.

[28] M.A. Hassan, S. Naderi, and A.R. Bushroa. "Lowvelocity impact damage of woven fabric composites: Finite element simulation and experimental verification". Materials and Design 53 (2014) 706718.

[29] Rahul S. Sikarwar, R. Velmurugan, N.K. Gupta. "Influence of fiber orientation and thickness on the response of glass/epoxy composites subjected to impact loading". Composites: Part B 60 (2014) 627636.

[30] M. Uyaner, M. Kara, A. Sahin. "Fatigue behavior of filament wound E-glass/epoxy composite tubes damaged by low velocity impact". Composites: Part B 61 (2014) 358-364.

\section{BIOGRAPHIES}

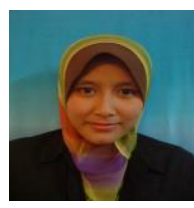

NoorshazlinRazali is a postgraduate student of Master of Science (MSc) in Aerospace Engineering at Universiti Putra Malaysia. Her area of study is damage detection in low velocity impact and high velocity impact in composite structures 
Dr. Mohamed Thariq Hameed Sultan is a senior lecturer in theAerospace Department, Faculty of Engineering, UniversitiPutra Malaysia. He is also the Head of Aerospace Manufacturing Research Centre (AMRC) and the Vice President of the Malaysian Society of Structural Health Monitoring (MSSHM). His areas of research are Structural Health Monitoring (SHM), damage detections and repairs, low and high velocity impact studies and composite materials 